\title{
A 50-year-old woman presented with severe reduction of vision and recurrent pain in right eye following cataract surgery
}

\author{
Md. Abdul Khaleque, Mohammad Afzal Mahfuzullah, Suprokash Sarkar, Abir Bin Sajj and \\ Md. Shafiqul Islam
}

\begin{tabular}{|c|c|}
\hline \multicolumn{2}{|l|}{ Article Info } \\
\hline $\begin{array}{l}\text { Department of Op } \\
\text { of Surgery, Banga } \\
\text { Medical Universit } \\
\text { Bangladesh }\end{array}$ & $\begin{array}{l}\text { thalmology, Faculty } \\
\text { andhu Sheikh Mujib } \\
\text { Shahbag, Dhaka, }\end{array}$ \\
\hline $\begin{array}{l}\text { For Corresponden } \\
\text { Md. Abdul Khaleq } \\
\text { khalequenat@yah }\end{array}$ & $\begin{array}{l}\text { e: } \\
\text { e } \\
\text { o.com }\end{array}$ \\
\hline Received: & 4 September 2019 \\
\hline Accepted: & 25 September 2019 \\
\hline Available Online: & 3 October 2019 \\
\hline
\end{tabular}

ISSN: 2224-7750 (Online) 2074-2908 (Print)

DOI: 10.3329/bsmmuj.v12i3.43330

Keywords: Cataract surgery; Neovascular glaucoma; Retinal vein occlusion; Vision

Cite this article:

Khaleque MA, Mahfuzullah MA, Sarkar S, Sajj AB, Islam MS. A 50-year-old woman presented with severe reduction of vision and recurrent pain in right eye following cataract surgery. Bangabandhu Sheikh Mujib Med Univ J. 2019; 12: $154-158$

\section{Copyright:}

The copyright of this article is retained by the author(s) [Atribution CC-By 4.0]

Available at:

www.banglajol.info

A Journal of Bangabandhu Sheikh Mujib Medical University, Dhaka, Bangladesh

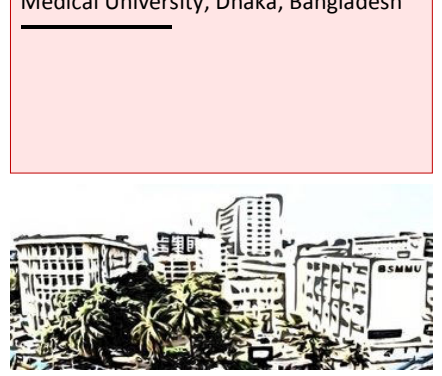

\section{Presentation of Case}

Dr. Abir Bin Sajj (MS Resident): A 50-year-old female, hailing from Patuakhali, was admitted at the Department of Ophthalmology for the management of severe reduction of vision and pain at the right eye for the last 7 months following cataract surgery at a government hospital. Her cataract surgery (small incision cataract surgery with PC-IOL implantation) of the right eye was performed on October 28, 2018. On the first post-operative day, she developed pain, redness and severe reduction of vision in the right eye. The following day, she was discharged with the advice of some medications like moxifloxacin, dexamethasone, bromfenac eye drops and oral acetazolamide and potassium. She was under weekly followup for the next 2 months but her vision did not improve and her pain also did not subside. After 4 months of surgery, she went to a local hospital where she was again prescribed oral acetazolamide and potassium with some antiglaucoma eye drops. With this medication, her pain slightly decreased but did not subside and there was no improvement in her vision. Later, she was referred to Dhaka for better management.

There was no history of any trauma, fever, cough, joint pain, weight loss or any irregular bowel movement. There was no previous history of any redness of eye before surgery. She was non-diabetic and normotensive.

On general examination she was ill-looking, blood pressure was $110 / 70 \mathrm{mmHg}$ and other vital parameters were within normal limit. All systemic examination revealed normal findings except ophthalmic examination.

On ocular examination, her best-corrected visual acuity on the right eye was reduced to hand movement with the presence of projection of rays from all 4 quadrants and on the left eye was $6 / 18$. Her pupillary light reaction was absent on the right eye and was pharmacologically dilated. Her ocular motility was full on all gazes on both eyes.

Dr. Md. Abdul Khaleque (Associate Professor): On slit lamp ((Topcon, Japan) examination of the right eye, eyelashes were matted. The conjunctiva was congested. The cornea edematous with ground glass appearance with multiple iris pigments on the endothelium, especially inferiorly and a suture was found placed at 8 O'clock position; shallow anterior chamber; new vessels present along the pupillary margin from 12 to 9 O'clock position with new vessels running in irregular direction (Figure 1A). The intraocular lens in the sulcus with iris pigments over the optics and posterior capsular tear (Figure 1B). On left eye, the findings were normal except the presence of lental opacity.

Her intraocular pressure was initially $40 \mathrm{mmHg}$

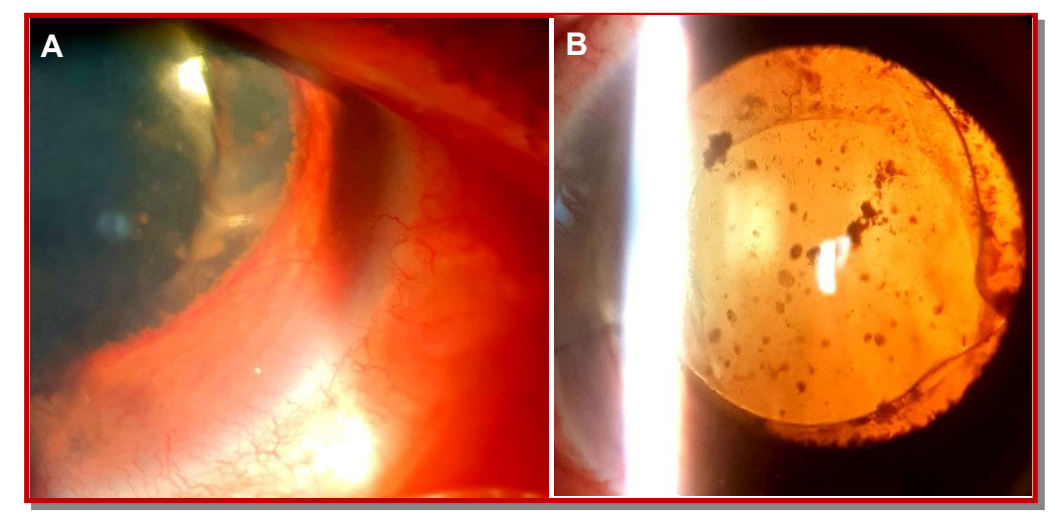

Figure 1: Diffuse illumination of the iris (A) and retroillumination of the right eye (B) using slit lamp biomicroscope 


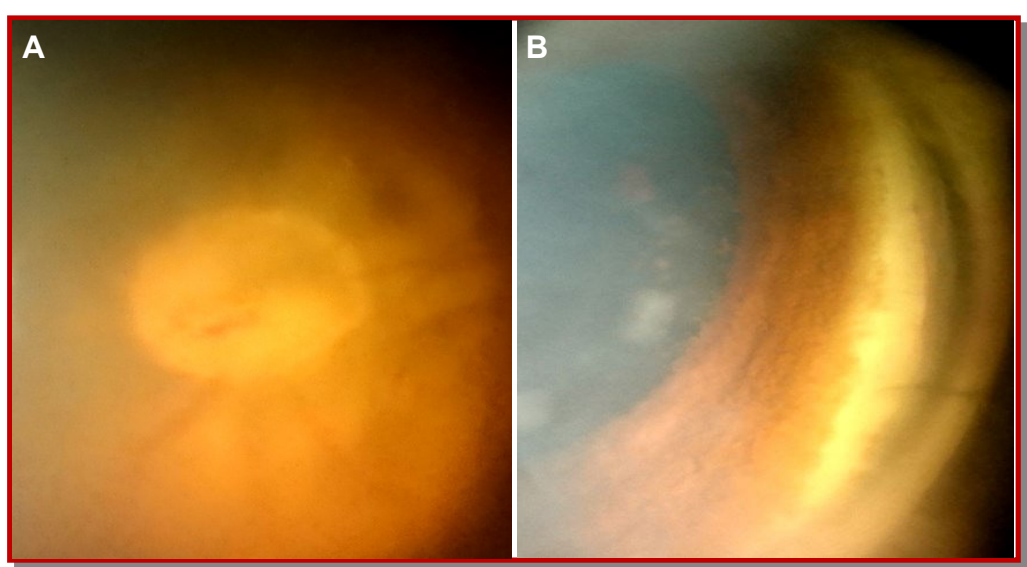

Figure 2: Showing optic disc by 90D condensing lens (Volk, USA) (A) and angle of the anterior chamber by 4 mirror gonioscope (Opticlear, India) (B)

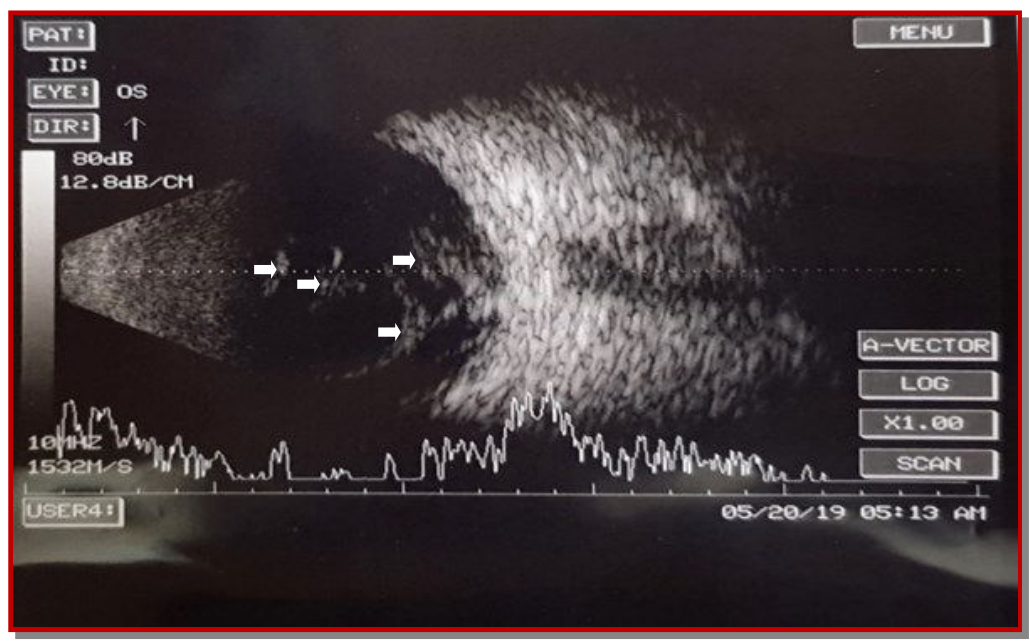

Figure 3: Some echogenic shadows in the vitreous cavity seen using B-scan of the right eye
Dr. Suprokash Sarkar (MS Resident): Laboratory data showed, slightly raised ESR, normal leukocyte count but slightly high lymphocyte count (Table I). Anti-HSV I showed positive titer for IgG (ISR 2.91) and IgM (ISR 2.22). Her lipid profile showed slightly elevated triglyceride level with normal other cholesterol levels. Her random blood glucose and $\mathrm{HbA} 1 \mathrm{C}$ levels were normal.

Dr. Mahfuzullah: Her B-scan (Veatech Ophthalmic Instrument, USA) of the right eye showed some echogenic shadows in the vitreous cavity which was suggestive of vitreous hemorrhage (Figure 3). Her MRI of the brain showed normal findings.

\section{Provisional Diagnosis}

Neovascular glaucoma due to central retinal vein occlusion (right eye)

\section{Differential Diagnosis}

\section{Inflammatory glaucoma}

Dr. Khaleque: Glaucoma is seen in about $20 \%$ of patients with uveitis. 1 Many types of inflammatory uveitis including herpetic uveitis can cause secondary glaucoma. One study shows patients with herpes simplex keratouveitis, $28 \%$ had intraocular elevation and $10 \%$ had glaucomatous damage. 2 As this patient showed positive titer for IgG and $\operatorname{IgM}$ against herpes simplex virus-1, so there is a chance of having inflammatory glaucoma.

\section{Pseudophakic glaucoma}

Dr. Khaleque: Secondary glaucoma may develop in a pseudophakic eye due to various reasons. In a study, ocular hypertension was noted in $9 \%$ of pseudophakic eyes. Out of them, only 3\% had permanent ocular hypertension resulting in chronic pseudophakic glaucoma. $\underline{3}$

medications (Tablet acetazolamide and timolol eye drop) and again raised to $43 \mathrm{mmHg}$ during admission. The intraocular pressure was measured by Goldmann applanation tonometer (Inami, Japan).

Dr. Mohammad Afzal Mahfuzullah (Assistant Professor): On fundoscopic examination of the right eye, the media was hazy. The color of the disc was pale. The disc margin was well-defined. The cup disc ratio was 0.9:1. The neuroretinal rim was almost obliterated in all the four quadrants (Figure 2A). Multiple dots and blot hemorrhages were present in all the four quadrants and the foveal reflex was absent. Her left eye fundus was normal.

Dr. Khaleque: On gonioscopic examination of the right eye, there was peripheral anterior synechiae present superiorly, nasally and inferiorly (Figure 2B). The new vessels were seen in the nasal, inferior and temporal angle over the trabecular meshwork. Her left eye findings were normal.

\section{Dr. Abdul Khaleque's Diagnosis}

Neovascular glaucoma due to central retinal vein occlusion (right eye)

\section{Discussion}

Dr. Khaleque: This morbid condition was postoperative. Hence, the angle-closure glaucoma might be subjected but this could be secondary angleclosure glaucoma. The treating physician prescribed antiglaucoma medication along with antibiotics and steroid as post-operative treatment. Naturally question comes what was the underlying cause of secondary glaucoma? She was not properly 


\begin{tabular}{|c|c|c|}
\hline \multicolumn{3}{|c|}{ Table I } \\
\hline \multicolumn{3}{|c|}{ Investigation reports of the patient } \\
\hline Parameters & Findings & References \\
\hline Random blood sugar (mmol/L) & 5.9 & $<11.1$ \\
\hline $\operatorname{HbA1C}(\%)$ & 5.9 & $<6$ \\
\hline $\begin{array}{l}\text { Erythrocyte sedimentation rate ( } \mathrm{mm} \\
\text { in first hour) }\end{array}$ & 30 & $<20$ \\
\hline Total white blood cell count $\left(/ \mathrm{mm}^{3}\right)$ & 9,000 & $4000-11,000$ \\
\hline \multicolumn{3}{|l|}{ Differential count } \\
\hline Neutrophil (\%) & 45 & $40-75$ \\
\hline Lymphocyte (\%) & 52 & $20-50$ \\
\hline Monocyte (\%) & 2 & $2-10$ \\
\hline Eosinophil (\%) & 1 & $1-6$ \\
\hline Serum cholesterol (mg/dL) & 180 & $<200$ \\
\hline High density lipoprotein (mg/dL) & 35 & $>35$ \\
\hline Low density lipoprotein (mg/dL) & 48 & $<100$ \\
\hline Triglyceride $(\mathrm{mg} / \mathrm{dL})$ & 165 & $<150$ \\
\hline C-Reactive protein $(\mathrm{mg} / \mathrm{L})$ & 1.9 & $<3$ \\
\hline
\end{tabular}

evaluated for her ailment as no records were available. She was discharged on 2nd post-operative day.

Seven months elapsed before admission into the Bangabandhu Sheikh Mujib Medical University Eye Unit ocular examination reveals that there was peripheral anterior synachiae along with new vessels in the angle.

Prof. Md. Shafiqul Islam: The most common cause of iris neovascularization is the ischemic retinopathy. There are different groups of disease-causing neovascularization. The groups are a) systemic vascular disease, b) ocular vascular disease, c) other ocular diseases, d) intraocular tumor, e) ocular therapy and f) trauma. Among the diseases, the most common causes are the carotid occlusive disease, diabetic retinopathy and central retinal vein occlusion. 4 Clinical evaluation of this patient excludes carotid occlusive disease and diabetic retinopathy. Hence, central retinal vein occlusion could be the underlying cause of neovascularization in this patient.

Iris neovascularization and neovascular glaucoma may occur in $45-85 \%$ of the eyes affected by ischemic central retinal vein occlusion and only in $5 \%$ of nonischemic eyes.

There is the formation of a fibrovascular membrane on the surface of the iris and trabecular meshwork of anterior chamber angle. Initially, the membrane covers the anterior chamber angle structure but subsequently it causes peripheral anterior synechia due to contraction. .5

Dr. Shish Rahman (Assistant Professor): What are the points in favor of central retinal vein occlusion?

Dr. Mahfuzullah: On indirect ophthalmoscopy, though media is hazy, there are dots and blot hemorrhages in all the four quadrants, which is suggestive of central retinal vein occlusion. It is the third most common blinding retinal disorder after diabetic retinopathy and branch retinal vein occlusion. $\underline{6}$

Dr. Shish Rahman: Is there any risk factors present for the central retinal vein occlusion?

Dr. Abir: In this patient, no risk factor is present. The patient is non-diabetic, non-hypertensive and lipid profile is normal.

Dr. Khaleque: The pathogenesis of central retinal vein occlusion is not yet well understood. It is thought to be a compartment syndrome, where central retinal artery, central retinal vein and optic nerve coexist in a $1.5 \mathrm{~mm}$ diameter area. The possible systemic factor can precipitate thrombus formation in addition to changes in compartmental structures. Thrombus, thus, forms in the lamina cribrosa in most or all the cases.7,8 Though there was no well-known risk factor for central retinal vein occlusion in this case, it could still happen before surgery. The patient may be unaware of uniocular visual loss. Intraocular surgery such as cataract extraction increases the risk for anterior segment neovascularization as the vascular endothelial growth factor is thought to move easier into the anterior chamber.

Prof. Md. Sharfuddin Ahmed: What were the complications occur during the initial surgery?

Dr. Abir: From the wound, it looks like that the surgeon could have planned phacoemulsification. Due to per-operative complication like posterior capsular rent and vitreous prolapse, the surgery was converted to small incision cataract surgery. The stitch at $8 \mathrm{O}^{\prime}$ clock position probably was due to wound closure of small incision cataract surgery.

Prof. Ahmed: Do you think trabeculectomy is necessary as if the intraocular pressure has been controlled with medication?

Dr. Khaleque: Trabeculectomy with mitomycin C could be a better option for this patient. 9 Trabeculectomy with mitomycin $\mathrm{C}$ combined with direct cauterization of the peripheral iris is an alternative option for the management of neovascular glaucoma. $\underline{10}$

Dr. Afzal: Current treatment options for ischemic central retinal vein occlusion include anti-vascular endothelial growth factor drugs, steroids, anticoagulants, laser treatments and a range of surgical interventions to minimize or delay the onset of complications associated with central retinal vein occlusion including macular edema and neovas- 
cularization.11, 12 Panretinal photocoagulation is effective in preventing neovascular glaucoma following ischemic central retinal vein occlusion. $\underline{\underline{13}}$

Dr. Khaleque: Intra-vitreal $\underline{14,15}$ as well as intracameral16 injection of bevacizumab (intracameral half dose) can be given. If the media becomes clear then panretinal photocoagulation LASER can be done.17 If the media remains hazy, then pars plana vitrectomy with endolaser can be done.18

Prof. S. A. Wadud: If we don't treat neovascularization what could be the complications?

Dr. Abir: Repeated hyphema or ocular pain can occur.

Dr. Khaleque: Pre-operative assessment is very crucial for cataract surgery. Detailed anterior segment examination with normal and dilated pupil by slit lamp, dilated fundus examination by slit lamp with $90 / 78$ D lens or indirect ophthalmoscope is mandatory. Intraocular pressure must be measured. Correlation of visual impairment and the extent of cataract are important. If the visual loss is greater than the extent of cataract. A further detailed evaluation is mandatory.

In this case, the surgeon, who did the initial surgery, probably missed the background pathology. If they could have been able to detect the central retinal vein occlusion and rubiosis iridis, then they would have to advise the initial intravitreal and intra-cameral anti-vascular endothelial growth factor. If possible, one session of panretinal photocoagulation prior to the surgery could be done. As panretinal photocoagulation remains the mainstay in controlling the neovascular drive and should be considered in all cases of neovascular glaucoma when retinal ischemia is present. $\frac{19,20}{\mathrm{In}}$ that case, the suffering of this patient could have been reduced.

\section{Final Diagnosis}

Pseudophakia with neovascular glaucoma due to central retinal vein occlusion (right eye)

\section{References}

1. Both SA, Kumar V, Raina UK, Ghosh B, Thakar M. Inflammatory glaucoma. Oman J Ophthalmol. 2011; 4:3-9.

2. Falcon MG, Williams HP. Herpes simplex keratouveitis and glaucoma. Trans Ophthalmol Soc UK. 1978; 98: 101-04.

3. Van Oye R, Gelisken O. Pseudophakic glaucoma. Int Ophthalmol. 1985; 8: 183-86.

4. Rath EZ, Frank RN. Shin DH. Kim C Risk factors for central retinal vein occlusion: A case control study. Ophthalmology 1992; 99: 509-14.

5. Hayreh SS, Rojas P, Podhajsky P, Montague P, Woolson RF. Ocular neovascularization with retinal vascular occlusion-III: Incidence of ocular neovascularization with retinal vein occlusion. Ophthalmology 1983; 90: 488-506.

6. The Central Retinal Vein Occlusion Study Group. Baseline and early natural history report: The central vein occlusion study. Arch Ophthalmol. 1993; 111: 1087-95.

7. Green WR, Chan CC, Hutchins GM, Terry JM. Central retinal vein occlusion: A prospective histopathologic study of 29 eyes in 28 cases. Trans Am Ophthalmol Soc. 1981: 89: 371-422.

8. Cioffi GA. Glaucoma (American Academy of Ophthalmology). San Francisco, Lifelong Education for the Ophthalmologist, 2010, pp 159-73.

9. Takihara $\mathrm{Y}$, Inatany M, Kawaji T, Fukushima M, Iwao $\mathrm{K}$, Iwao $\mathrm{M}$, Tanihara $\mathrm{H}$. Combined intravitreal bevacizumab and trabeculectomy with mitomycin $C$ versus trabeculectomy with mitomycin $C$ alone for neovascular glaucoma. J Glaucoma. 2011; 20: 196-201.

10. Elgin U, Berker N, Batman A, Simsek T, Cankaya B. Trabeculectomy with mitomycin $\mathrm{C}$ combined with direct cauterization of peripheral iris in the management of neovascular glaucoma. J Glaucoma. 2006; 15: 466-70.

11. Bradshaw SE, Gala S, Nanavaty M, Shah A, Mwamburi M, Kefalas P. Systematic literature review of treatments for management of complications of ischemic central retinal vein occlusion. BMC Ophthalmol. 2016; 16: 104.

12. Ehlers JP, Spirn MJ, Lam A, Sivlingam A, Samuel MA, Tasman W. Combined intravitreal bevacizu$\mathrm{mab} /$ paretnal photocoagulation versus panretinal photocoagulation alone in the treatment of neovascular glaucoma. Retina 2008; 28: 696-702.

13. Megargal LE, Brown GC, Augsburger JJ, Donoso LA. Efficacy of panretinal photocoagulation in preventing neovascular glaucoma following ischemic central retinal vein obstruction. Ophthalmology 1982; 89: 780-84.

14. Ayman A Alkawas, Ezzat A Shahien, Atef M Hussein. Management of neovascular glaucoma with panretinal photocoagulation, intravitreal bevacizumab, and subsequent trabeculectomy with mitomycin C. J Glaucoma. 2010; 19: 622-26.

15. Yazdani S, Hendi K, Pakravan M, Mahdavi M, Yaseri M. Intravitreal bevacizumab for neovascular glaucoma: A randomized controlled trial. J Glaucoma. 2009; 18: 632-37.

16. Ha JY, Lee TH, Sung MS, Park W. Efficacy and safety of intracameral bevacizumab for treatment of neovascular glaucoma. Korean J Ophthalmol. 2017; 31: 538-47.

17. Hatem M Marey, Amin F Ellakwa. Intravitreal 
bevacizumab with or without mitomycin C trabeculectomy in the treatment of neovascular glaucoma. Clin Ophthalmol. 2011; 5: 841-45.

18. Chang LH, Wang NK, Chen YP, Yeung L, Hwang YS, Chan KJ, Wu WC, Chan TL. Photocoagulation reduces the occurrence of neovascular glaucoma in central retinal vein occlusion with vitreous haemorrhage. Retina 2013; 33: 798-802.

19. Hayreh SS. Neovascular glaucoma. Prog Retin Eye Res. 2007; 26: 470-85.

20. Vein T. Natural history and clinical management of central retinal vein occlusion. Arch Ophthalmol. 1997; 115: 486-91. 